\title{
IMPROVING STUDENTS' VOCABULARY MASTERY USING WORD MAPPING STRATEGY
}

\author{
Oleh: Satuna Indah Wardani \\ (The Teacher of State Vocational School 1 Pamekasan)
}

\begin{abstract}
:
The purpose of this study was to find out whether the word mapping strategy was able to improve the students' vocabulary mastery. The process of mastering is mainly affected by the worst thought of the vocational students who said that English as the most difficult subject to learn and was often tracked into boring condition since theywere not involved in the process of learning. Thisstudy was conducted by using classroom action research in two cycles and each cycle consisted of four meetings. The subject of the research was the third grade of Accounting Department at State Vocational School 1 Pamekasan which consisted of 34 students. The research was carried out for one month. The instruments used to obtained primary data and the secondary data were vocabulary test, the students' observation sheets, and questionnaire of the respondent.The result of test in preliminary until the test in cycle two showed that there was the improvement of the number of students who passed the test. Hopefully, this outcome will certainly be useful for both teachers and students in which its harmony will give the progress for learning English, especially vocabulary mastery.
\end{abstract}

Key words:

Vocabulary, word mapping

Introduction

The

basic

purpose

of communication is to convey the intended message of the speaker toward the listener. Language is a mean of communication in human life plays an important role to improve the quality of all aspects in social life. In Indonesia, English is the first foreign language which is taught formally from the elementary to the university level.

Despite the fact that English as a foreign language, the vocational school students are expected to master their English communicative competence as one of the provisions to be professional workers at national or multinational companies and institutions. For the students of Vocational School, English must be their ability to reach the wide world. As the world becomes more interconnected, the need to communicate in a readily understood language becomes more urgent than ever.

The role of English language plays a big part in bringing people together from around the world. English 


\section{Satuna Indah Wardani}

language training becomes an important part of vocational high school students as it provides them with advantages in further learning and in getting a job.

In order to communicate well, the students need to have large vocabulary. As Thornbury (2002: 16) stated that without grammar very little can be conveyed, without vocabulary nothing can be conveyed. Because vocabulary is a vital aspect in language, it appears in every skill of language listening, speaking, reading and writing skill. Mastering vocabulary is very important for the students who learn English as a foreign language. That is why everybody who learns English or a certain language should know the words. The mastery of vocabulary can support them in speaking when they are communicating to people can write and translate the meaning of words when they definite English. If they do not know the meaning of words, they will not be able to speak, write and translate anything English. The students can be said gaining progress in English, the mastery of vocabulary.

In short, large vocabulary makes a significant contribution to almost all of the aspect of language. Nevertheless, many students in Vocational school have very limited vocabulary.it was found problem that most of students were lack of vocabulary. They found difficulties in using English as the target language.Certainly, learning requires both motivation and strategy optimally.

Vocabulary is one of English components is defined as the total number of words in a language. Large vocabularies help us to express our ideas precisely, vividly and without repeating ourselves in composition (Burton, S.H, 1985: 98). Moreover, Vocabulary is very essential for success to comprehend the language well, speak better, or composed a good writing; it is expected that learners have to increase their vocabulary by around 1000 words a year (Nation, P. 1990: 22).As Vocabulary is very important thing because it can listing of the words used in some enterprise, a language user's knowledge of words and the system of techniques or symbols serving as a means of expression (as in arts or crafts); "he introduced a wide vocabulary of techniques". Vocabulary also the set of words they are familiar with in a language. A vocabulary usually grows and evolves with age, and serves as a useful and fundamental tool for communication and acquiring knowledge. Learning vocabulary is one of the first steps of learning a second language, yet one never reaches the last step of vocabulary acquisition. Whether in one's native language or a second language, the acquisition of new vocabulary is a continuous process. Many methods can help one acquire new vocabulary.That is why teaching vocabulary plays an important role to communicate in English successfully.

Teaching vocabulary is one of the basic elements in achieving all four language skills. Similarly, Jordan 
(1997: 149) also states that Teaching vocabulary is such an important task in teaching English because vocabulary achievement relates to all language learning and it is of concern to all four language skills.

Vocabulary mastery is very important to build understanding of meaningful reference. John W. Shamrock (1991: 298) states that: understanding the utterances of others requires us to make meaningful a string of sound that strikes our ears requires us to make inferences, using our knowledge of the situation and of language itself - it's sound, syntax, and semantics.

The most important of learning English fluently is mastering the vocabulary. By having a lot of vocabularies, we can improve our English.As Vocabulary building is very important in any language learning not only because it has a close correlation with the intellectual maturity of the learners but also the fact that it helps a great deal in improvement of the four language skills of the students.

In advanced steps, vocabulary acquisition is manipulated to make meaningful sentences. Gerot and Wignel (1994) state that: confirm that vocabulary in functional grammars view language as resource for making meaning.

State Vocational School 1 is one of the oldest vocational school in Pamekasan in which the students have problem with their vocabulary. When the teacher asked them to say something in English, they didn't know to respond. Their vocabulary was limited so they were difficult to comprehend the meaning of text. They couldn't compose their writing task successfully. So, it can be concluded that vocabulary emerged as the cause of the most difficulty for students.

Even though it had been established for a long time, the teacher found failure and difficulties to stimulate the students to be interested and to use English in simple practice. That condition was too often to be found.

Based on the problem above, the teacher should find the best or the effective strategy to teach English vocabulary more effective, easier and effortless. A strategy is potentially a conscious plan for solving what to the individual presents itself as a problem in reaching a particular goal (Farch, C. and Kasper, G. ,1980: 47-118). Concerning to the characteristics of the students which they are able to be bored easily, need to stimulate their thought, arouse their responses in English, so it is important to create the class situation which can motivate the students to study by using a certain strategy.

\section{Word Mapping Strategy}

One of the strategies is word mapping. Word mapping is one of the most powerful approaches to teaching vocabulary because it engages students in thinking about word relationships 


\section{Satuna Indah Wardani}

(Graves, M. In A. E. Farstrup \& S. J. Samuels (Eds.), 2008:56-79). The strategy promotes students' active exploration of word relationships, thereby leading to a deeper understanding of word meanings by developing their conceptual knowledge related to words.Word maps help students to make connections between their prior knowledge and the new words. They show conceptual relationships between words. By showing these relationships students can modify their existing framework of knowledge (schema) and more effectively construct meaning when they meet the words in the text. Furthermore, word map is a graphic rendering of a word's meaning. Typically, it has the form of having the vocabulary word in the central portion of the graphic organizer, and three separate sections for the three main questions about the word linked to it. They are What is it? is one of the questions linked to the new vocabulary in the center of the graphic organizer to help the student relate the term to existing knowledge. For example, for the term "doll," this question would be answered with toy or plaything. Then What is it like? is answered with a description of the term. A doll would be described as a play baby or a play model to dress with different clothes. The last is What are some examples? is a question for which students think about what they know about the term and apply it to those things that fit the description and meaning. Examples of dolls would be a Barbie and Cabbage Patch doll.

Moreover, Vocabulary mapping is a graphic organizer, which enables students to expand definitions of words. As Schwartz and Raphael (1998) in Santa designed the vocabulary mapping strategy to encourage students to move from simpledictionary-like statements to more complex critical thinking definitions that shows relationships: What is it (category)? What is it like (properties)? What are examples (illustrations)?

Procedure:

1. Show students an overhead of the vocabulary-mapping organizer. Point out that in order to develop a meaningful definition, the map needs to contain three relationships: "What is it? What is it like? What are some? examples?"

2. To model this strategy, the teacher begins by identifying a familiar vocabulary word that can be easily mapped. (Examples: yogurt, rain forest, shoes)

3. Teacher writes the word on map.

4. Ask "What is it?" Record selected student responses on map.

5. Ask "What is it like?" Record student responses on map.

6. Ask "What are some examples?" Record student responses on map.

7. Explain to students that the definition now includes properties, categories, and examples.

Word Mapping Strategy can be most effective most effective used before, during, and after reading. It also 
can used to introduce new vocabulary before reading. As a follow-up to reading and discussion of the text, the teacher encourages students to develop their word maps by using the new information they acquired through reading. Students may also use word maps during reading, as they add new ideas and words to further build word knowledge and extend understanding of word relationships.

Considering the explanation above, the researcher wants to give a solution especially to improve the students' vocabulary mastery, so that later the students will be able to use English well in. The solution is by doing research in teaching vocabulary using Word mapping. Reutzel and Cooter (2008) suggest the use of word maps with English language learners for vocabulary instruction because it offers a way for them to demonstrate and connect their prior knowledge to new concepts and, at the same time, serves as a useful tool to categorize information.

In doing this research, the researcher applied the Word Mapping strategy in teaching vocabulary provided by games. It will make the students more interested and enjoyable in learning process. Hopefully that the students' vocabulary mastery will be improved. By using games will help the students to memorize the words and motivate them to learn vocabulary.

Based on the background above, it is important to formulate the problem of this study as:" Does using Word
Mapping significantly improve the students vocabulary mastery?"

\section{Method}

The research was conducted in the third grade of Accounting department in State Vocational School 1 Pamekasan in the academic year 2013/2014 at the even semester which consisted of 6 boys and 28 girls. Every student had the same tests from the teacher. The strategy done by the research including the activities in introducing the idea of using word mapping to improve vocabularymastery and how to analyze the students' work. The design of this study is a classroom action research. Mc. Niff (1992) stated that action research is an intervention in personal practice to bring about improvement and it has a special kind of research problem. In conducting the classroom action research, the researcher used Kemmis and Mc. Taggart (1996) in which each cycle consists of four steps: planning of action, implementing of action, observing and evaluation analysis and reflection.

The implementation of action research is emphasized during the process of learning.This dealed with preparing observation sheets and field note to collect the data during the assessment process as well as designing the criteria of success use in this study. After the planning of the action was finish, the next step was the implementation, the research act as the 


\section{Satuna Indah Wardani}

observer. The researcher observed how the research implemented word mapping to improve students' mastery on vocabulary. In the last step that was reflection, based on the result of the data analysis, the researcher made reflection to judge whether this classroom action research needed to be continued or not. In the next meeting, the researcher implemented the revising the plan of the previous meeting. The researcher preparedword mapping as strategy in learning vocabulary mastery.

The instruments used to obtained primary data and the secondary data were vocabulary test, the students' observation sheets, and questionnaire of the respondent. In this study, there were three tests which were done during the research. They were prelimenerytest, test in cycle 1 , and 2 . Those test were administered to measure about the improvement of their vocabulary mastery from the cycle 1 and cycle 2. The observation was administered to measure the characteristics of the students towards the application of using word mapping, and questionnaire was administered to support the data of the students' improvement in vocabulary mastery.

The procedure of collecting data was conducted by using two cycles in eight meetings. There are four stages namely; plan, action, observation and reflection.

In doing this strategy, the researcher used the following steps of implementing word mapping (Antonacci, A. Patricia and O'callaghan, M. Chatherine, 2012:95-96) :

1. Select words for vocabulary instruction. Prepare for vocabulary instruction by carefully selecting the words to be taught. Choose words by considering the readings and the words that are key to understanding the text.

2. Project a blank word map. Model how to construct a word map and demonstrate to students how to use the word map for building and exploring word relationships.

3. Write the key words on the word map. In each blank, write and say the key word that will be taught.

4. Use a think-aloud to model how to explore relationships between words. Use the think-aloud strategy to (a) demonstrate how to explore word relationships; (b) think about the meaning of the key word or related words; (c) model how to further the meaning of the word by examples and nonexamples, or synonyms and antonyms, of the word; (d) find the definition of the word in a glossary or dictionary and find its use in context or a discussion with another student about the word's meaning; and (e) draw a picture of the word to illustrate its meaning in context.

5. Record ideas that have been used to explore the word meanings and relationships.

6. Students are directed to use the word maps during and after reading to add 


\section{Satuna Indah Wardani}

information about the key words.Students use the word maps for recording new information while they are reading. After reading, they may further develop their word meanings by looking for dictionary definitions, drawing pictures of words, and adding new words from their readings.

7. Students share their maps with others.

The research could be said successful if it achieved the determined criterion (criteria of success). The researcher used the Minimal Mastery Criterion (KKM) 75 to be success or not.

\section{Findings and Discussion}

The researcher found that the students' mastery in vocabulary was low. It could be shown in the percentage of the class unsuccess was47.3\%. It meant that the students who failed the vocabulary test on the preliminary study were $47.3 \%$. It meant that all students were unsuccessful. (see the table of students' score in Vocabulary test for each cycle)

The result of the test in the cycle one and two was different. It had showed the improvement of the students continuously. The percentage of test 1 in cycle 1 was $71.20 \%$ and in cycle 2 was $78.80 \%$. It showed that the teaching and learning process was successful. The result of students' score percentage also shows the great improvement that is $78.80 \%$ and that indicated higher than the minimal mastery criterion (75\%).

The researcher concluded that improving students' vocabulary mastery using word mapping could increase the student's ability in mastering vocabulary. It means that improving students' vocabulary mastery using word mapping in State Vocational School 1 Pamekasan (Accounting department 1) is success in classical category.

The table of students' score in Vocabulary test for each cycle

\begin{tabular}{|c|c|c|c|c|c|}
\hline NO & $\begin{array}{c}\text { STUDENTS' } \\
\text { NAME }\end{array}$ & $\begin{array}{c}\text { Preliminery } \\
\text { Test }\end{array}$ & $\begin{array}{c}\text { Test 1 } \\
\text { (cycle } \\
1)\end{array}$ & $\begin{array}{c}\text { Test 2 } \\
\text { (cycle 2) }\end{array}$ & MEAN \\
\hline 1 & AL & 40 & 67 & 76 & 61 \\
\hline 2 & AMI & 56 & 65 & 78 & 66.3 \\
\hline 3 & AS 1 & 50 & 67 & 78 & 65 \\
\hline 4 & AS 2 & 50 & 70 & 75 & 65 \\
\hline 5 & CDH & 48 & 67 & 77 & 64 \\
\hline 6 & DAP & 60 & 70 & 80 & 70 \\
\hline 7 & DY & 45 & 68 & 75 & 62.7 \\
\hline 8 & FI & 50 & 65 & 80 & 65 \\
\hline 9 & FF & 50 & 67 & 87 & 68 \\
\hline
\end{tabular}

OKARA, Vol. 1, Tahun X, Mei 2015 


\begin{tabular}{|c|c|c|c|c|c|}
\hline 10 & $\mathrm{HF}$ & 65 & 70 & 85 & 73.3 \\
\hline 11 & JMY & 30 & 75 & 90 & 65 \\
\hline 12 & $\mathrm{KH}$ & 60 & 67 & 80 & 69 \\
\hline 13 & $\mathrm{KK}$ & 40 & 77 & 78 & 65 \\
\hline 14 & LYS & 40 & 70 & 69 & 59.7 \\
\hline 15 & LA & 50 & 70 & 90 & 70 \\
\hline 16 & LS & 50 & 68 & 75 & 64.3 \\
\hline 17 & LAS & 40 & 67 & 75 & 60.7 \\
\hline 18 & MIR & 45 & 60 & 78 & 61 \\
\hline 19 & $\mathrm{NIQH}$ & 50 & 66 & 80 & 65.3 \\
\hline 20 & $\mathrm{NRI}$ & 40 & 76 & 76 & 64 \\
\hline 21 & $\mathrm{NSH}$ & 30 & 75 & 80 & 61.7 \\
\hline 22 & RASA & 35 & 78 & 80 & 64.3 \\
\hline 23 & RAYE & 40 & 80 & 85 & 68.3 \\
\hline 24 & $\mathrm{RRF}$ & 55 & 77 & 80 & 70.7 \\
\hline 25 & RWT & 65 & 60 & 67 & 64 \\
\hline 26 & STF & 50 & 69 & 75 & 64.7 \\
\hline 27 & STH & 50 & 79 & 80 & 69.7 \\
\hline 28 & STR & 45 & 77 & 80 & 67.3 \\
\hline 29 & SHD & 40 & 78 & 80 & 66 \\
\hline 30 & SHAD & 40 & 78 & 80 & 66 \\
\hline 31 & SSA & 40 & 80 & 80 & 66.7 \\
\hline 32 & SCS & 50 & 70 & 75 & 65 \\
\hline 33 & SYH & 50 & 70 & 75 & 65 \\
\hline 34 & YKH & 50 & 78 & 80 & 69.7 \\
\hline \multicolumn{2}{|c|}{ TOTAL SCORE } & 1599 & 2421 & 2679 & \\
\hline & MEAN & 47.03 & 71.20 & 78.80 & \\
\hline
\end{tabular}

From the data above, it could be seen that there were 13 students (38 $\%$ in cycle 1passing the minimal mastery criterion ( $\geq 75$ ). And there were only two students who failed the test or got lower than the minimal mastery criterion.

The collecting data which was taken from the students' observation sheet and questionnaire could be said that word mapping made the students interested. The students were more enthusiastic in learning difficult vocabularies. They looked enjoyable in the class that applied the word mapping strategy.

After using word word mapping strategy, the researcher saw that there were good responses from the students. The students were more 


\section{Satuna Indah Wardani}

enthusiastic in studying English (vocabulary) by using word mapping . In addition it could be used to avoid the boredom in the class. In general, the researcher concludes that improving students' vocabulary mastery using word mapping strategy can increase the student's ability in mastering vocabulary. It means that improving students' vocabulary mastery using word mapping in State Vocational School 1 Pamekasan (Accounting department 1 ) is success.

\section{Conclusion and Suggestion}

Based on the explanation above, it can be concluded that the way to increase the students' ability to master vocabulary by using word mapping is more helpful. The students need to enrich their vocabulary to be able to communicate, write, listen and comprehend the reading in English well.

There were none of 34 students who passed at the vocabulary test in the preliminary test. To improve the students' vocabulary mastery, the researcher taught them using word mapping in a classroom action research.

From the research In the first cycle, There were $38 \%$ (13) of students who passed the vocabulary test. It is indicated percentage of the cycle one is unsuccessful. Because of the weakness of the cycle one was planned the research goes to second cycle. In the second cycle, it was found improving vocabulary mastery using word mapping had motivated the students to learn more effectively and enjoyable through their active participation in using English. The result of the study in the second cycle, there were $94 \%$ (32) students who passed the vocabulary test. It was higher than the level criteria of success $(75 \%)$. It means that the research is succesful since the criteria of success is $75 \%$ for the percentage of the students passing the minimal mastery criterion (KKM) classically.

Finally, it can be concluded that the use of word mapping strategy can improve students' vocabulary mastery. The researcher realizes that the research is still very far from perfection. the researcher hopes that this study is able to be used as the contribution to do further research, especially in dealing with the study on vocabulary mastery with the different subject and different design . Moreover, the other researchers will develop this research using different perspective and different object. 


\section{Satuna Indah Wardani}

\section{References}

Antonacci, A. Patricia and O'callaghan, M. Chatherine.2012. Promoting Literacy Development $\quad(50$ Research-Based Strategies for K-8 Learners.

Burton, S.H. 1985. Mastering English Language. Milan Press Ltd. Milan.

Farch, C. and Kasper, G. (1980). Processes and strategies in foreign language learning and communication. Interlanguage Studies Bulletin, 5, 47-118.

Gerot, Linda and Wignel. 1994. Making Sense of Functional Grmmar. Antipodal Educational Enterprise.

Graves, M. (2008). Instruction on individual words: One size does not fit all. In A. E. Farstrup \& S. J. Samuels (Eds.), What research has to say about vocabulary instruction (pp. 56-79). Newark, DE: International Reading Association

Jordan, R.R.199. English for Academic Purposes. Cambridge: CUP.

Kemmis and Taggart 1996.Action Research: $A$ short modern technology. Victoria: Deakin University Press.

McNiff.1992. Action Research: Principle and Practice. London: Routledge.Nation, P. 1990. Teaching and Learning Vocabulary. New York: NewburyHouse. P.22

Reutzel, D. R., \& Cooter, R. B. (2008). Teaching children to read: The teacher makes the difference(5th ed.). Upper Saddle River, NJ: Merrill Prentice Hall
Santa, C.M; Havens, L.T. \& Maycumber, E.M. (1988). Project CRISS: Creating independence through student-owned strategies. Iowa: KendalllHunt.

Scott Thornbury (2002) cited in David Wilkins .1972. How To Teach Vocabulary. (London: Person Education Limited, 2002).

Shamrock, John.W. 1991. Physiology: The Science of Mind and Behaviour ( $3^{\text {rd }}$ ed.). Dallas: Winc.Publisher. 